\title{
Behaviour of Copper during High Temperature Oxidation of Steel Containing Copper
}

\author{
Yasumitsu KONDO \\ Environment \& Process Technology Centre, Nippon Steel Corporation, 20-1 Shintomi, Futtsu-city, Chiba 293-8511 Japan.
}

(Received on March 24, 2004. accepted in final form on June 2, 2004)

\begin{abstract}
It is well known that copper causes the hot shortness problem in steels and is a difficulty when using steel scrap in the steelmaking process. This is due to the property of copper enriching at the scale/metal interface and precipitating there as liquid during the high temperature oxidation of steels containing copper.

In this paper, the behaviour of copper during oxidation is investigated. A steel containing copper is oxidized and the distribution of copper in the scale is examined. It is found that copper is not only enriched at the scale/metal interface, but also exists in the upper magnetite $\left(\mathrm{Fe}_{3} \mathrm{O}_{4}\right)$ layer as a state of solid solution and along the grain boundaries of the wustite layer as a metal. From these results an assumption has been proposed that the liquid copper migrates from the scale/metal interface to $\mathrm{Fe}_{3} \mathrm{O}_{4}$ layer along the grain boundaries.

Quantitative analysis revealed that the copper amount in the scale is greater than that at the scale/metal interface. Further analysis discovered that the amount of copper eliminated from the steel by oxidation is greater than the total amount of copper detected in the sample i.e. at the scale/metal interface, in the $\mathrm{Fe}_{3} \mathrm{O}_{4}$ layer, and along the grain boundaries in the scale.
\end{abstract}

KEY WORDS: high temperature oxidation; copper; hot shortness; scale; magnetite; wustite; grain boundary; scrap; mass balance.

\section{Introduction}

Recycling of steel scraps accumulates copper in steel resources. Copper is difficult to remove during the steelmaking processes and often causes hot shortness problems. When steel slabs are reheated in furnaces, copper is enriched at the scale/metal interface and precipitated as liquid metal during this processes. Following the hot-rolling process, liquid copper penetrates into the steel grain boundaries and causes cracks at the steel surface. Steel recycling is thought to be important from the environmental point of view. It is necessary to develop processes to suppress this problem. Some methods have already been proposed.

The addition of some elements has a good effect on this problem. The addition of nickel is useful and has been explained to increase the solubility of copper in $\gamma$-Fe which reduces the precipitation of liquid copper at the scale/metal interface. ${ }^{1-4)}$ The addition of silicon also has been beneficial to this problem. ${ }^{5,6)}$ The addition of silicon reduces the susceptibility of hot shortness at more than $1473 \mathrm{~K}$, since the liquid precipitation of copper is trapped in the liquid oxide formed by silicon. ${ }^{5}$ The silicon addition also decreases the amount of precipitated copper by the occlusion of copper in the oxide scale and reduces the susceptibility of hot shortness at $1373 \mathrm{~K}$, where the liquid $\mathrm{Fe}-\mathrm{Si}$ oxide does not formed. ${ }^{6)}$ It is reported that the addition of phosphorus, carbon, and boron are favourable elements for hot shortness. These elements are thought to change the distribution of liquid copper in the scale, steel grain size, and the tough- ness of steel grain boundary for the crack propagation. ${ }^{7,8)}$

Controlling the reheating conditions such as temperature and atmosphere are also beneficial effects on this problem. The reheating temperature $1373 \mathrm{~K}$ is most severe for hot shortness. At conditions of higher or lower temperatures the sensitivity of surface crack is reduced. ${ }^{5,7)}$ The oxidizing atmosphere is also an influence; water vapour in the atmosphere increases the number of crack on the steel surface. ${ }^{9)}$

In order to control the amount and the distribution of enriched copper, it is necessary to understand the behaviour of copper during the scale formation. In this study, detailed and quantitative investigations were performed to reveal the behaviour of copper during the high temperature oxidation of steels containing copper.

\section{Experimental}

A steel containing 0.1 mass $\%$ copper was used for the experiments. The analyzed compositions of the material are shown in Table 1. Specimens were cut to rectangular shapes of $30 \mathrm{~mm} \times 30 \mathrm{~mm} \times 4 \mathrm{~mm}$. Oxidation was performed in an infrared heating furnace at $1473 \mathrm{~K}$ in an atmosphere of $2 \% \mathrm{O}_{2}+12 \% \mathrm{H}_{2} \mathrm{O}+86 \% \mathrm{~N}_{2}$; mass gain during oxidation was measured. The oxidizing time was $7200 \mathrm{~s}$ and will now be referred to as long time oxidation. In order to clarify the scale structure at the early stage of oxidation, another short time oxidation test was carried out. This oxidation time was $120 \mathrm{~s}$ (short time oxidation) and the same atmosphere is used $\left(2 \% \mathrm{O}_{2}+12 \% \mathrm{H}_{2} \mathrm{O}+86 \% \mathrm{~N}_{2}\right)$. 
Table 1. Chemical composition of the steel containing copper (mass \%).

\begin{tabular}{|c|c|c|c|c|c|c|c|c|c|c|c|c|}
\hline $\mathrm{C}$ & $\mathrm{Si}$ & $\mathrm{Mn}$ & $\mathrm{P}$ & $\mathrm{S}$ & sol-Al & $\mathrm{N}$ & $\mathrm{Ti}$ & $\mathrm{B}$ & $\mathrm{Cu}$ & $\mathrm{Sn}$ & $\mathrm{Ni}$ & $\mathrm{Cr}$ \\
\hline 0.0020 & 0.009 & 0.067 & 0.012 & 0.0065 & 0.039 & 0.0020 & 0.037 & 0.0003 & 0.096 & 0.012 & 0.038 & 0.056 \\
\hline
\end{tabular}

Examinations of the oxidized specimen were performed using optical microscopy, electron probe micro analysis (EPMA), and transmission electron microscopy (TEM). The TEM samples were made using focused ion-beam technology (FIB). These samples were set on molybdenum meshes in the TEM in order to avoid the copper background signals.

The amounts of enriched copper at the scale/metal interface were obtained from quantitative EPMA analysis. The procedure used to measure the amount of copper in the scale is shown in Fig. 1. Following oxidization, the sample was mounted in resin and a rectangular specimen with scale and metal was cut from the sample. To analyze the scale, the metal surface was completely abraded and the resin was removed by dissolving in N,N-dimethylformamide. The obtained scale sample was chemically dissolved in the acids of $\mathrm{HCl}, \mathrm{H}_{2} \mathrm{SO}_{4}$ and $\mathrm{HNO}_{3}$. The copper concentration in the acid solution was measured by inductively coupled plasma spectrometer (ICP).

\section{Results and Discussion}

\subsection{Copper Distribution in the Scale}

Results of an EPMA line analysis on the cross section of the scale formed by the long time oxidation are shown in Fig. 2. The oxygen concentration profile indicates that the scale contains three layers: hematite $\left(\mathrm{Fe}_{2} \mathrm{O}_{3}\right)$, magnetite $\left(\mathrm{Fe}_{3} \mathrm{O}_{4}\right)$, and wustite $(\mathrm{FeO})$. The copper profile shows an interesting phenomenon that copper is not only enriched at the scale/metal interface but also exists in the upper part of the $\mathrm{Fe}_{3} \mathrm{O}_{4}$ layer.

In order to clarify the state of copper in the $\mathrm{Fe}_{3} \mathrm{O}_{4}$ layer, TEM analysis was performed on the cross section of the scale formed by the long time oxidation near the $\mathrm{Fe}_{2} \mathrm{O}_{3} / \mathrm{F}_{3} \mathrm{O}_{4}$ interface. The TEM image shown in Fig. 3 reveals two layers in the scale. Energy dispersive spectrometry (EDS) and electron diffraction analysis were performed at three points in each layer. Electron diffractions results indicate that the left side is a part of the $\mathrm{Fe}_{3} \mathrm{O}_{4}$ layer and the right side is a part of the $\mathrm{Fe}_{2} \mathrm{O}_{3}$ layer (Table 2). EDS results reveal that copper is contained in the $\mathrm{Fe}_{3} \mathrm{O}_{4}$ layer, however, copper does not exist in the $\mathrm{Fe}_{2} \mathrm{O}_{3}$ layer (Table 2). Furthermore, these results also indicate that copper exists in $\mathrm{Fe}_{3} \mathrm{O}_{4}$ as a state of solid solution.

Figure 4 shows the relationship between the temperatures and oxygen pressures at which the metals of copper and iron equilibrate to their oxides. $\mathrm{Fe}_{3} \mathrm{O}_{4}$ is stable between the lines of $\mathrm{Fe}_{3} \mathrm{O}_{4} / \mathrm{Fe}_{2} \mathrm{O}_{3}$ and that of $\mathrm{FeO} / \mathrm{Fe}_{3} \mathrm{O}_{4}$. At $1473 \mathrm{~K}$, the equilibrium oxygen pressure of $\mathrm{Cu} / \mathrm{Cu}_{2} \mathrm{O}$ is located in the region where $\mathrm{Fe}_{3} \mathrm{O}_{4}$ is stable. Interpretation of Fig. 4 explains how copper exists as oxide in the upper part of $\mathrm{Fe}_{3} \mathrm{O}_{4}$ layer.

It is well known that $\mathrm{Fe}_{3} \mathrm{O}_{4}$ has spinel structure. The spinel oxide of $\mathrm{Fe}-\mathrm{Cu}-\mathrm{O}$ has a complete solid solution system between $\mathrm{Fe}_{2} \mathrm{CuO}_{4}$ and $\mathrm{Fe}_{2} \mathrm{FeO}_{4}$. This further explains

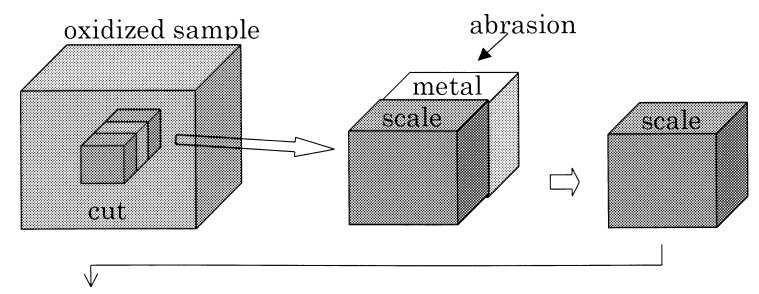

$\mathrm{HCl}+\mathrm{HNO}_{3} \rightarrow$ heating $\rightarrow$ addition of $\mathrm{H}_{2} \mathrm{SO}_{4} \rightarrow$ heating $\rightarrow$ addition of $\mathrm{HNO}_{3} \rightarrow$ heating $\rightarrow$ cooling $\rightarrow$ addition of $\mathrm{HCl} \rightarrow$ heating $\rightarrow$ cooling $\rightarrow$ addition of water $\rightarrow$ ICP measurement

Fig. 1. The procedure to measure the amount of copper in the oxide scale.
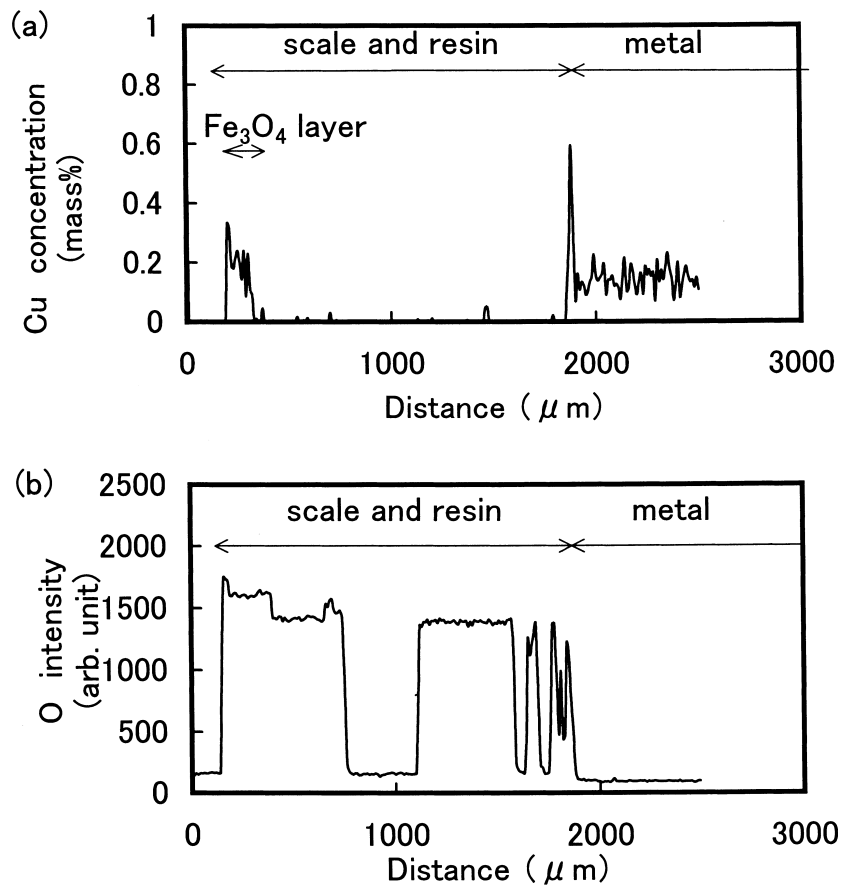

Fig. 2. The EPMA line analysis of the cross section of the oxide scale. (a) Copper profile. (b) Oxygen profile.

why copper may exist as a state of solid solution in the upper part of the $\mathrm{Fe}_{3} \mathrm{O}_{4}$ layer.

\subsection{Migration of Liquid Copper through the Scale}

The result of X-ray diffraction on the surface of the scale formed by the short time oxidation is shown in Fig. 5. Only the $\mathrm{FeO}$ scale is formed on the steel during the short time oxidation. It was founded that the oxidation kinetics follows the linear law and only the $\mathrm{FeO}$ scale is formed at the early stage of the oxidation at the conditions with a relatively low oxygen concentration atmosphere. ${ }^{10)}$

At the early stage of oxidation, the concentration of enriched copper at the scale/metal interface is low and the liquid copper has not yet precipitated at the interface (Fig. 6(a)). After the scale becomes thicker, liquid copper precipitates at the interface (Fig. 6(b)). Considering the results that $\mathrm{Fe}_{3} \mathrm{O}_{4}$ is not formed at the early stage of oxidation and 
the assumption that copper is not precipitated at the early stage, it is considered that copper migrates from the scale/metal interface to $\mathrm{Fe}_{3} \mathrm{O}_{4}$ layer through the $\mathrm{FeO}$ layer.

\subsection{Path of Copper Migration through the Scale}

In order to find a path of copper migration through the scale, TEM analysis was performed on the scale formed by the long time oxidation. A detailed EPMA mapping was performed on the $\mathrm{FeO}$ layer prior to the TEM analysis. Areas where $\mathrm{FeO}$ contains copper in the layer were determined. Using FIB, a small piece of the oxide sample containing copper was removed and made into a TEM sample;

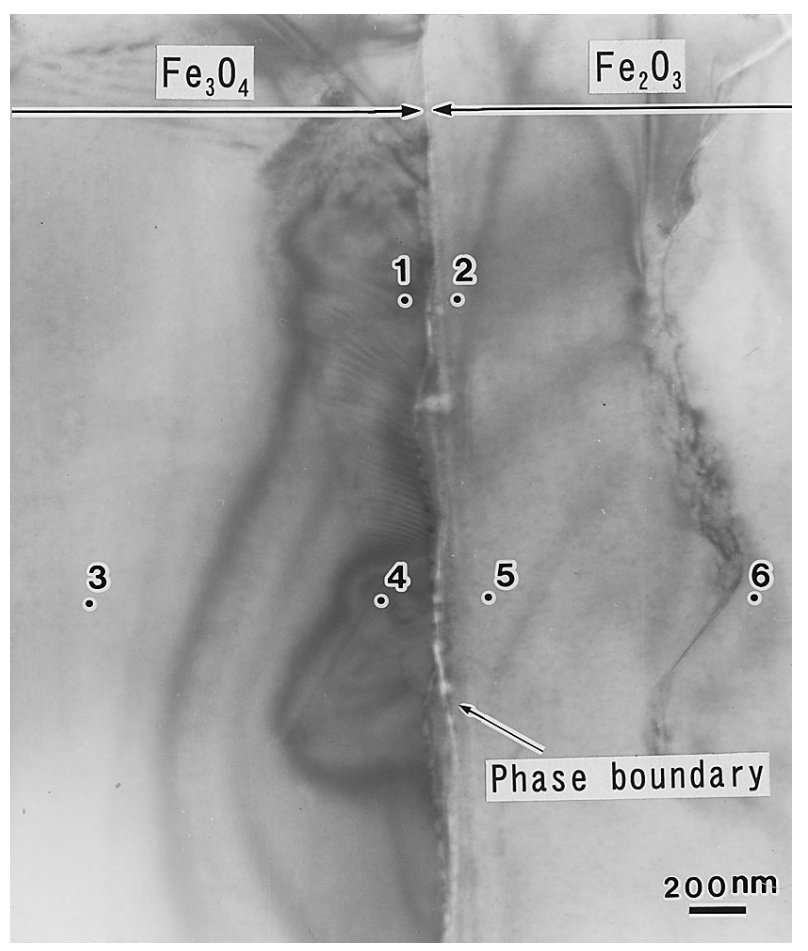

Fig. 3. The TEM image of the cross section of the oxide scale.

Table 2. Identified species at the points in the TEM image of Fig. 3 by the EDS analyses and the electron diffraction patterns.

\begin{tabular}{lll}
\hline Location & Species & Detection of $\mathrm{Cu}$ \\
\hline Point 1 & $\mathrm{Fe}_{3} \mathrm{O}_{4}$ & $\mathrm{Cu}$ is detected \\
Point 2 & $\mathrm{Fe}_{2} \mathrm{O}_{3}$ & $\mathrm{Cu}$ is not detected \\
Point 3 & $\mathrm{Fe}_{3} \mathrm{O}_{4}$ & $\mathrm{Cu}$ is detected \\
Point 4 & $\mathrm{Fe}_{3} \mathrm{O}_{4}$ & $\mathrm{Cu}$ is detected \\
Point 5 & $\mathrm{Fe}_{2} \mathrm{O}_{3}$ & $\mathrm{Cu}$ is not detected \\
Point 6 & $\mathrm{Fe}_{2} \mathrm{O}_{3}$ & $\mathrm{Cu}$ is not detected \\
\hline
\end{tabular}

(a)

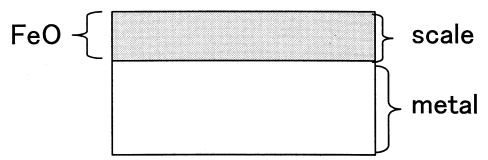

there were two copper particles in the TEM sample. Figure 7 shows a TEM image of the scale containing a copper particle. The copper particles, metals with a f.c.c. structure, are located at the grain boundaries in the $\mathrm{FeO}$ layer as determined by the EDS and the electron diffraction pattern (Table 3). The diameter of the copper particles is about $100 \mathrm{~nm}$. These results suggest that liquid copper migrates along the grain boundaries of $\mathrm{FeO}$ scale.

A proposed process of copper migration through the scale and dissolves in $\mathrm{Fe}_{3} \mathrm{O}_{4}$ layer as a state of solid solution is schematically shown in Fig. 6. Liquid copper migrates through the scale because metal phase is stable in the $\mathrm{FeO}$ layer (Fig. 4). After reaching the $\mathrm{Fe}_{2} \mathrm{O}_{3} / \mathrm{Fe}_{3} \mathrm{O}_{4}$ interface, the liquid copper is oxidized by $\mathrm{Fe}_{2} \mathrm{O}_{3}$, dissolved in the $\mathrm{Fe}_{3} \mathrm{O}_{4}$ layer, and diffuses inward in the $\mathrm{Fe}_{3} \mathrm{O}_{4}$ layer.

Tanaka et al. ${ }^{11)}$ reported that liquid copper has extremely good wettability to $\mathrm{FeO}$. He also explained that the good wettability may be due to the chemical absorption of oxy-

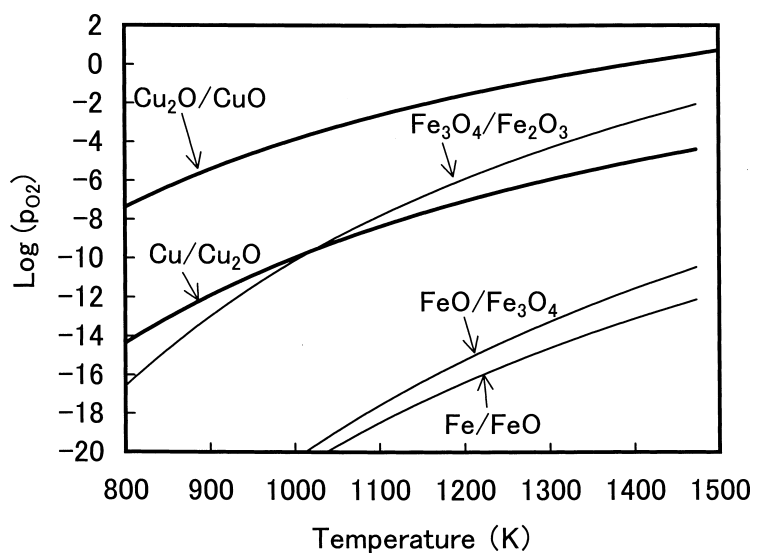

Fig. 4. The equilibrium oxygen pressure of copper, iron, and their oxides.

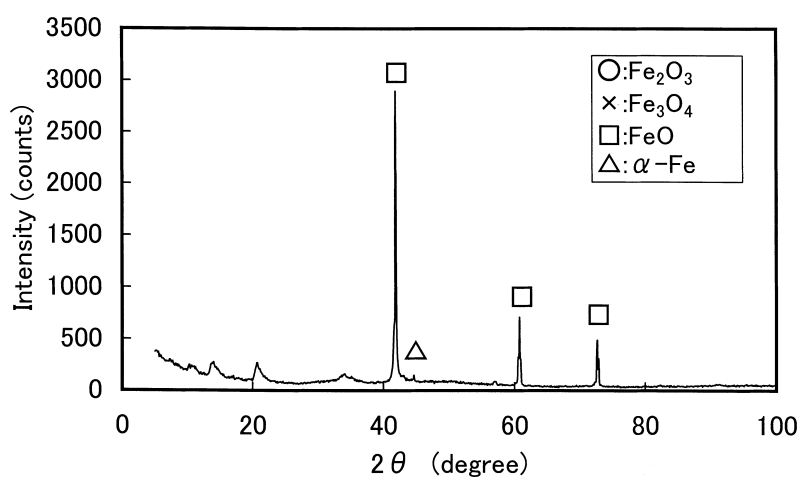

Fig. 5. The X-ray diffraction pattern measured on the scale surface of the steel oxidized in $2 \% \mathrm{O}_{2}+12 \% \mathrm{H}_{2} \mathrm{O}+86 \% \mathrm{~N}_{2}$ at 1473 for $120 \mathrm{~s}$

(b)

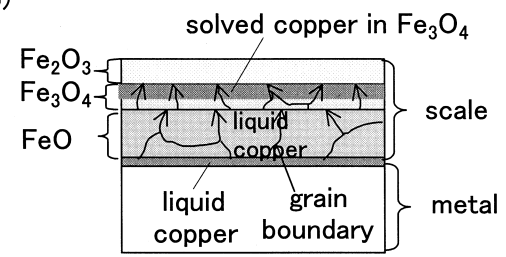

Fig. 6. The schematic drawings of copper behaviour during the oxidation of steels containig copper. (a) Early stage of the oxidation. (b) Later stage of the oxidation. 


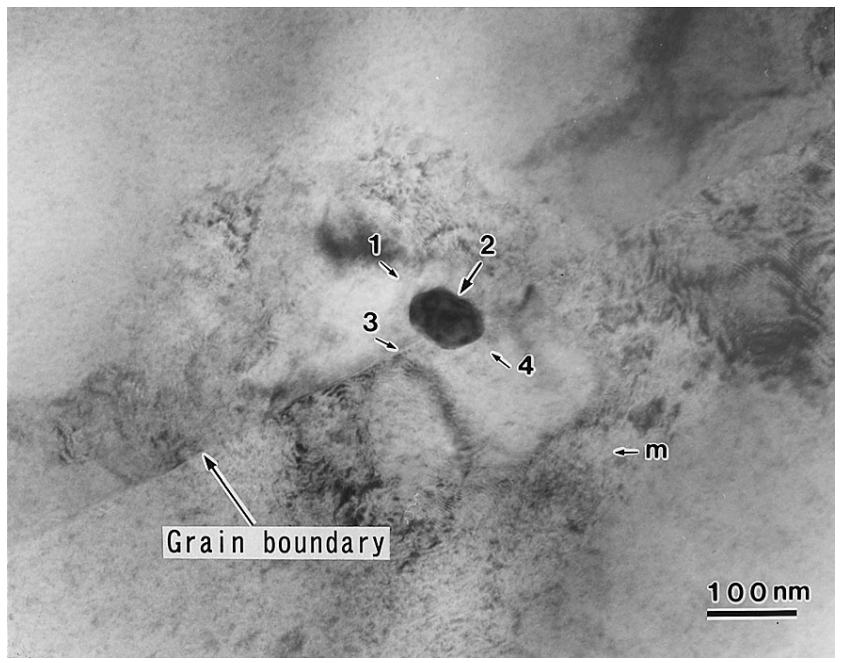

Fig. 7. A TEM image at an $\mathrm{FeO}$ grain boundary of the scale.

Table 3. Identified species at the points in the TEM image of Fig. 7 by the EDS analyses and the electron diffraction patterns.

\begin{tabular}{ll}
\hline Location in fig. 7 & Species \\
\hline Point 1 & $\mathrm{Fe}_{3} \mathrm{O}_{4}$ \\
Point 2 & $\mathrm{Cu}$ \\
Point 3 & $\mathrm{Fe}_{3} \mathrm{O}_{4}$ \\
Point 4 & $\mathrm{Fe}_{3} \mathrm{O}_{4}$ \\
Point $\mathrm{m}$ & $\mathrm{FeO}$ \\
\hline
\end{tabular}

gen in liquid copper. Referring again to Table 2, the oxide around the copper particle and along the $\mathrm{FeO}$ grain boundary is $\mathrm{Fe}_{3} \mathrm{O}_{4}$. The oxide around the other copper particle (not shown) is also $\mathrm{Fe}_{3} \mathrm{O}_{4}$. It is considered that released oxygen from the copper particle during the cooling process oxidizes the $\mathrm{FeO}$ to $\mathrm{Fe}_{3} \mathrm{O}_{4}$. However, there are no pores or no space at the grain boundary as shown in Fig. 7. Since good wettability does not fully explain the migration mechanism of copper through the scale, further research is necessary to reveal the mechanism.

\subsection{Mass Balance of Copper during the Oxidation}

Copper behaviour during the oxidation of steels containing copper should be explained quantitatively. Copper is nobler metal than iron. When a steel containing copper is oxidized, copper is not oxidized and enriched at the scale/metal interface. The copper enriched at the interface is henceforth referred to as eliminated copper. Copper remaining near the interface will be referred to as copper at the interface while both of copper migrating into the scale and copper existing in the $\mathrm{Fe}_{3} \mathrm{O}_{4}$ layer (Figs. 2 and 7) is called copper in the scale. The amount of the eliminated copper should be equal to the total of the copper amount in the scale and that at the interface.

The amount of the eliminated copper by the oxidation is calculated from the mass gain after the oxidation and the copper concentration of the base steel. The mass gain after the oxidation is $0.187 \mathrm{~g} \mathrm{~cm}^{-2}$ in this experiment. If the oxide consists of $95 \% \mathrm{FeO}, 4 \% \mathrm{Fe}_{3} \mathrm{O}_{4}$, and $1 \% \mathrm{Fe}_{2} \mathrm{O}_{3}$ in volume percent, the iron consumed by oxidation is

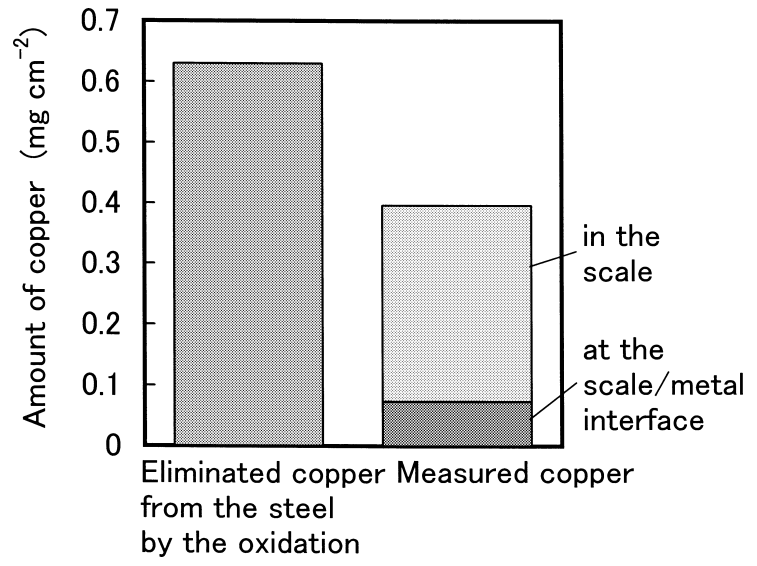

Fig. 8. The comparison between the amount of eliminated copper by the oxidation from the steel and that of measured copper in the scale.

$0.65 \mathrm{~g} \mathrm{~cm}^{-2}$. Multiplying the copper concentration by this value, the eliminated copper amount of $0.63 \mathrm{mg} \mathrm{cm}^{-2}$ is obtained.

The amount of enriched copper at the scale/metal interface is obtained from the quantitative EPMA measurement results. The copper concentration near the interface is integrated in the copper enriched region. The region has $17 \mu \mathrm{m}$ depth at the interface. The enriched copper is calculated at $0.073 \mathrm{mg} \mathrm{cm}^{-2}$ by multiplying the density of iron by the integrated value.

The enriched copper at the scale metal interface tends to diffuse backward into the metal. The diffusion coefficient of copper at $1473 \mathrm{~K}$ is $6.3 \times 10-11 \mathrm{~cm}^{2} \mathrm{~s}^{-1}{ }^{12)}$ The Eq.(1) expresses the mean square diffusion displacement $\overline{\Delta x^{2}}$, here $D$ is diffusion coefficient and $t$ is time.

$$
\overline{\Delta x^{2}}=2 D t
$$

the mean square diffusion displacement for the $7200 \mathrm{~s}$ oxidation at $1473 \mathrm{~K}$ is $90 \mu \mathrm{m}^{2}$. The scale/metal interface is also moving towards the inside of the metal, as iron is consumed by the oxidation. The distance is about $1100 \mu \mathrm{m}$ that is obtained from the value of consumed iron by the oxidation $0.65 \mathrm{~g} \mathrm{~cm}^{-2}$. These calculation results indicate that most back diffusing copper remains near the scale/metal interface. The enriched copper amount at the interface 0.073 $\mathrm{mg} \mathrm{cm}{ }^{-2}$ includes most of the amount of back diffusing copper.

Figure 8 shows the mass balance after the long time oxidation. Two important points are deduced from these results. Firstly, the amount of copper in the scale is much greater than that at the interface. Details of copper existing in the outer part of the scale have never been previously examined. This study clearly shows the existence of copper in the upper $\mathrm{Fe}_{3} \mathrm{O}_{4}$ layer. Increasing the amount of copper into the scale could prove beneficial for the hot shortness problem.

Secondly, the total amount of detected copper, which is the total of the copper amount in the scale and the copper amount at the interface, is less than that of the eliminated copper from the steel by the oxidation. The behaviour of the remainder of copper is still unknown.

The possibility exists that copper may be evaporating from the scale surface at the early stage of the oxidation 


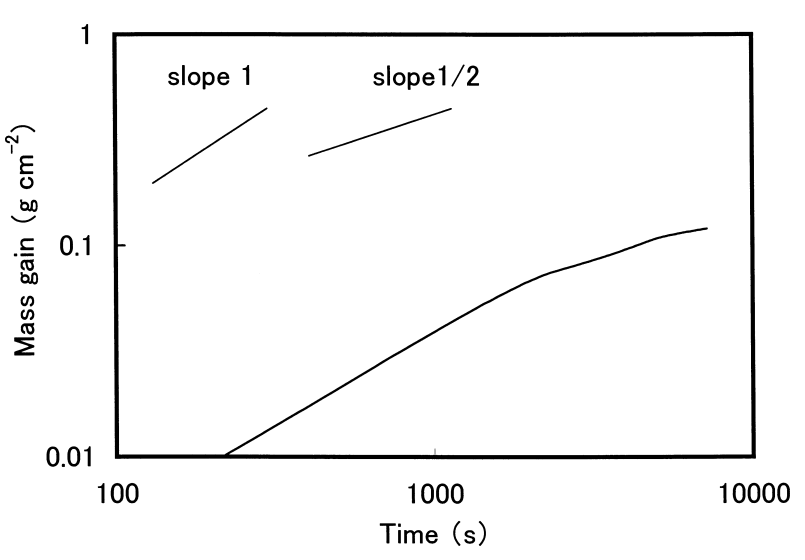

Fig. 9. The mass gain during the oxidation.

into the atmosphere. It was confirmed that only $\mathrm{FeO}$ scale is formed at the early stage shown in Fig. 5. If liquid copper migrates through the $\mathrm{FeO}$ scale, and reaches the surface of the scale, then the copper could evaporate and oxidized to oxide in the atmosphere.

When the liquid copper equilibrates to copper gas at $1473 \mathrm{~K}$, the equilibrium partial pressure of copper gas is $5.2 \times 10^{-6} \mathrm{~atm}$. The evaporation flux in vacuum condition is expressed in Eq. (2), where $p$ is equilibrium partial pressure, $m$ is mass of molecule, $k$ is Boltzmann's constant, and $T$ is temperature.

$$
\Gamma=\left(\frac{m}{2 \pi k T}\right)^{1 / 2} p
$$

If liquid copper reaches the scale surface and the equilibrate to the atmosphere at the surface at $1473 \mathrm{~K}$, the evaporation flux of copper is $4.8 \times 10^{-5} \mathrm{~g} \mathrm{~cm}^{-2} \mathrm{~s}^{-1}$.

Figure 9 shows the oxidation kinetics during the oxidation. In the early stage the kinetics are linear. The oxide scale formed in the linear law region consists of only FeO. ${ }^{10)}$ The duration of the linear law region is about $1800 \mathrm{~s}$ (Fig. 9).

The evaporation flux and the duration of the linear law are enough great to explain the missing copper amount, $0.23 \mathrm{mg} \mathrm{cm}^{-2}$. However, it is very difficult to estimate the actual evaporation flux. The pressure of the atmosphere in the actual oxidation is $1 \mathrm{~atm}$. This factor decreased the evaporation flux tremendously. Furthermore, as the actual atmosphere gas is flowing, the evaporation rate is increased. Further research is also necessary to understand the whole behaviour of copper during oxidation. It gives us a new idea or method to decrease enriched copper at the scale/metal interface and suppress the hot shortness problem.

\section{Conclusion}

This study examines the behaviour of copper during the oxidation of steel containing copper. The following conclusions are drawn:

(1) When copper containing steel is oxidized at $1473 \mathrm{~K}$, copper is not only enriched at the scale/metal interface, but also distributes in the upper part of $\mathrm{Fe}_{3} \mathrm{O}_{4}$ layer as a state of solid solution. Copper also exists along the $\mathrm{FeO}$ grain boundaries of the scale as metallic copper. It is believed that liquid copper migrates from the scale/metal interface to $\mathrm{Fe}_{3} \mathrm{O}_{4}$ layer along the grain boundaries of the scale.

(2) The copper amount in the scale, which is the total of the copper amount in the $\mathrm{Fe}_{3} \mathrm{O}_{4}$ layer and that along the grain boundaries in the scale, is greater than that at the scale/metal interface.

(3) The copper amount eliminated from the steel by the oxidation is greater than the detected copper, which is the total of the copper amount at the scale/metal interface, that in the $\mathrm{Fe}_{3} \mathrm{O}_{4}$ layer and that along the grain boundaries in the scale. This result suggests the possibility that some amount of copper evaporates from the surface.

\section{Acknowledgement}

I would like to thank Mr. Toyohiko Sato and Mr. Tetsuya Suzuki at Nippon Steel Technoresearch Corporation (NSTR), who performed the TEM analyses. I also thank Mr. Hiroki Hamada at NSTR, who perform EPMA analysis on the oxide scales.

\section{REFERENCES}

1) A. Nicholson and J. D. Murray: J. Iron Steel Inst., 203 (1965), 1007.

2) S. Akamatsu, K. Koyama and O. Akisue: CAMP-ISIJ, 7 (1994), 1712.

3) N. Imai, N, Komatsubara and K. Kunishige: ISIJ Int., 37 (1997), 217.

4) N. Imai, N, Komatsubara and K. Kunishige: ISIJ Int., 37 (1997), 224.

5) T. Kajitani, M. Wakoh, N. Tokumitsu, S. Ogibayashi and S. Mizoguchi: Tetsu-to-Hagané, 81 (1995), 185.

6) S. Seo, K. Asakura and K. Shibata: ISIJ Int., 37 (1997), 240.

7) K. Shibata, S. Seo, M, Kaga, H. Uchino, A. Sasanuma, K. Asakura and C. Nagasaki: Mater. Trans., 43 (2002), 292.

8) C. Nagasaki, H. Uchino, K. Shibata, K. Asakura and M. Hatano: Tetsu-to-Hagané, 89 (2003), 332.

9) M. Hatano, K. Kunishige and Y. Komizo: Tetsu-to-Hagané, 89 (2003), 659.

10) Y. Kondo and M. Kameda: CAMP-ISIJ, 15 (2002), 1080.

11) T. Tanaka, N. Takahira and S. Hara: CAMP-ISIJ, 16 (2003), 1376.

12) K. Majima, S. Orito and H. Mitani: J. Jpn. Inst. Met., 41 (1977), 1207 